\title{
Early elevated serum gamma glutamyl transpeptidase after liver transplantation is associated with better survival
}

\section{[version 1; peer review: 2 approved]}

\author{
Edris M Alkozai1,2, Ton Lisman 1,2, Robert J Porte2, Maarten W Nijsten³ \\ ${ }^{1}$ Surgical Research Laboratory, University Medical Center Groningen, University of Groningen, 9713 GZ Groningen, The Netherlands \\ ${ }^{2}$ Hepatobiliary Surgery and Liver Transplantation Section, Department of Surgery, University Medical Center Groningen, University \\ of Groningen, 9713 GZ Groningen, The Netherlands \\ ${ }^{3}$ Department of Critical Care, University Medical Center Groningen, University of Groningen, 9713 GZ Groningen, The Netherlands
}

V1 First published: 03 Apr 2014, 3:85

https://doi.org/10.12688/f1000research.3316.1

Latest published: 15 Aug 2014, 3:85

https://doi.org/10.12688/f1000research.3316.2

\section{Abstract}

Background: Gamma glutamyl transpeptidase (GGT) is a membrane bound enzyme that plays a key role in the synthesis of the antioxidant glutathione. Epidemiological studies have linked high GGT with an increased risk of morbidity and cardiovascular mortality. In contrast, GGT is usually elevated in liver transplant recipients that experience good outcomes.

Aims: To study if and how GGT is correlated with mortality following liver transplantation.

Methods: We analyzed the prognostic relevance of serum GGT levels during the early and late postoperative period after liver transplantation in 522 consecutive adults. We also studied alanine aminotransferase, aspartate aminotransferase, and total bilirubin levels.

Results: Early after transplantation, the peak median (interquartile range) GGT levels were significantly higher in patients who survived more than 90 days compared to non-survivors: 293 (178-464) vs. 172 (84-239) U/l, $p<0.0001$. In contrast, late after transplantation, GGT levels were significantly lower in patients who survived more than 5 years than those who did not $(p<0.01)$. The pattern of GGT levels also differed from those of alanine aminotransferase, aspartate aminotransferase, and total bilirubin early after transplantation, while these patterns were congruent late after transplantation. KaplanMeier survival analysis showed that early after transplantation the higher the GGT levels, the better the 90-day survival $(p<0.001)$. In contrast, late after transplantation, higher GGT levels were associated with a lower 5-year survival $(p<0.001)$.

Conclusions: These paradoxical findings may be explained by the time-dependent role of GGT in glutathione metabolism. Immediate postoperative elevation of GGT may indicate a physiological systemic response while chronic elevation reflects a pathological response.

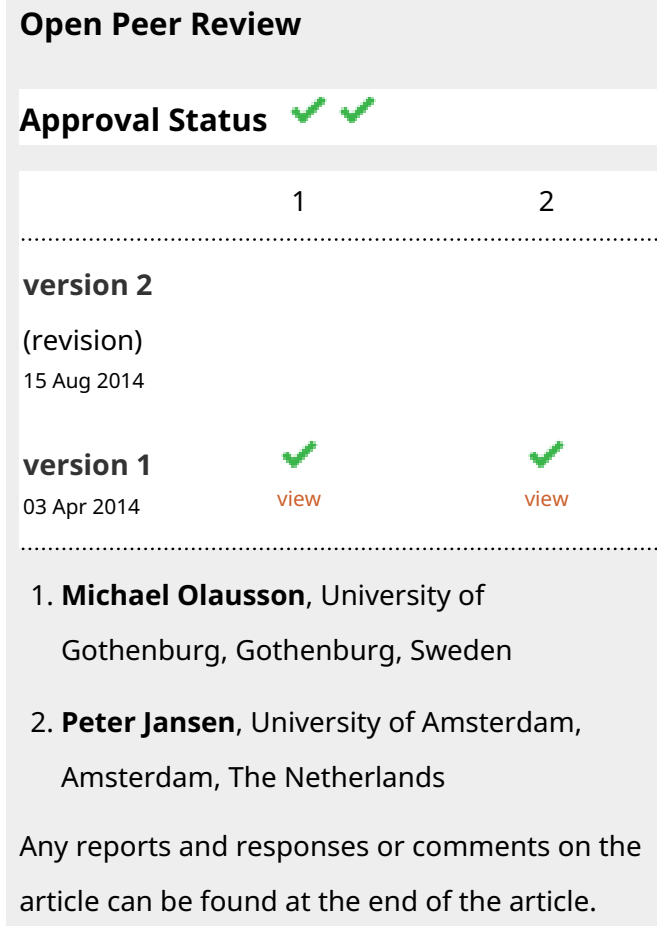

1. Michael Olausson, University of Gothenburg, Gothenburg, Sweden

2. Peter Jansen, University of Amsterdam, Amsterdam, The Netherlands Any reports and responses or comments on the article can be found at the end of the article. 


\section{Keywords}

Gamma glutamyl transpeptidase, alanine aminotransferase, aspartate aminotransferase, bilirubin, liver transplantation, oxidative stress,

glutathione, survival

umca This article is included in the University Medical

\section{Center Groningen collection.}

Corresponding author: Maarten W Nijsten (m.w.n.nijsten@umcg.nl)

Competing interests: No competing interests were disclosed.

Grant information: This study was sponsored in part by a Mozaiek grant of the Dutch Organisation of Scientific Research (017.007.115) to Edris Alkozai.

The funders had no role in study design, data collection and analysis, decision to publish, or preparation of the manuscript.

Copyright: @ 2014 Alkozai EM et al. This is an open access article distributed under the terms of the Creative Commons Attribution License, which permits unrestricted use, distribution, and reproduction in any medium, provided the original work is properly cited. Data associated with the article are available under the terms of the Creative Commons Zero "No rights reserved" data waiver (CC0 1.0 Public domain dedication).

How to cite this article: Alkozai EM, Lisman T, Porte RJ and Nijsten MW. Early elevated serum gamma glutamyl transpeptidase after liver transplantation is associated with better survival [version 1; peer review: 2 approved] F1000Research 2014, 3:85

https://doi.org/10.12688/f1000research.3316.1

First published: 03 Apr 2014, 3:85 https://doi.org/10.12688/f1000research.3316.1 


\section{Introduction}

Gamma glutamyl transpeptidase (GGT) is a membrane-bound enzyme that is essential for the synthesis of glutathione (GSH), a key antioxidant ${ }^{1}$. In clinical practice elevated serum GGT is generally used as an indicator of liver disease, such as biliary obstruction, alcohol consumption, and exposure to certain medical drugs ${ }^{1}$. Recently, several epidemiological studies have shown that a higher serum GGT level, even within the normal range, is associated with cardiovascular risk factors such as hypertension, hypertriglyceridemia, obesity, type 2 diabetes mellitus and stroke, as well as certain types of cancer $^{2-10}$. In contrast to these studies, we observed that after surgery for ruptured abdominal aortic aneurysm ${ }^{11}$ or after liver resection ${ }^{12}$, GGT is transiently increased in patients who had a good outcome. In these short-term observational studies GGT level was inversely related to other liver laboratory parameters such as aspartate aminotransferase (ALT), alanine aminotransferase (AST) as well as total bilirubin $(\mathrm{TBI})^{11,12}$. We observe that in the early postoperative period after a liver transplantation (LT) a transient gradual increase in GGT also occurs. How early and late postoperative changes in serum GGT are related to survival is not known.

Here we present a study in which we assessed the relationship between early (postoperative day seven) elevated GGT levels with early and late survival (i.e. survival within the 90 days and five years post-LT, respectively). We also evaluated the relationship between late (six months postoperatively) elevated GGT levels with late survival.

In addition, we studied the early and late post-LT kinetics of GGT, AST, ALT, and TBI in patients who survived more than 90 days and in patients who did not. Likewise, these kinetics were compared with long-term survival.

\section{Materials and methods}

\section{Study population}

We conducted a single center cohort study on 522 first liver transplant patients. All LTs performed between January 1990 and August 2009 were included; excluded were pediatric patients (age $<17$ years), second or subsequent LT, and first LT patients who underwent a re-LT within 90 days of their first LT. Since obstructive mechanisms such as non-anastomotic stricture (NAS), acute graft rejection, and cholestatic disorders might influence GGT and TBI levels, we also specifically repeated our analysis with and without such patients. This study was performed in accordance with Dutch legislation and the local ethical committee guidelines.

\section{Study variables}

Patient characteristics and variables related to the perioperative management and the surgical procedure were obtained from a prospectively collected database. These included age, sex, body mass index, Karnofsky score, indication for LT, preoperative MELD (Model for End-Stage Liver Disease) score (calculated from preoperative laboratory measurements), length of hospital stay, cold ischemia time, warm ischemia time, duration of operation, combined transplant (kidney or lung), acute rejection, graft type, the number of units of allogeneic and autologous red blood cell units (RBC with $1 \mathrm{U}$ containing $300 \mathrm{ml}$ ) and fresh frozen plasma (FFP with $1 \mathrm{U}$ containing $250 \mathrm{ml}$ ), donor type, type of venous and bile duct anastomosis, and NAS within 90 days and within one year.
When necessary, the hospital files were reviewed to complete all relevant clinical parameters.

The kinetics of serum GGT and other liver function variables early and late post-LT

We studied the levels of serum GGT and other liver variables postoperatively in two ways. Early postoperatively, up to postoperative day (POD) 30, we studied the levels of GGT (reference values; 0-40 U/l), ALT (0-45 U/l), AST (0-40 U/l), and TBI (0-17 $\mu \mathrm{mol} / \mathrm{l})$ over time in patients who survived more than 90 days after LT compared to those who did not. Late postoperatively (i.e. 90 days and beyond), we evaluated the levels of these variables at three months, six months, and one year in patients who survived more than five years compared to those patients who did not.

\section{Survival analysis and elevated GGT early and late following LT}

To evaluate the clinical relevance of early and late elevated GGT levels, we generated tertiles of low, intermediate, and high GGT levels based on equal percentiles. GGT levels at POD 7 were used to study the relationship between early elevated GGT levels and both 90-day and five-year survival. GGT levels at six months following LT were used to study the relationship of late elevated GGT with five-year survival. The last observation date for the status of patient survival for the study cohort was August 23, 2012.

\section{Statistical analysis}

Statistical analyses were performed using the statistical software package SPSS 20 (IBM SPSS, Chicago, IL). Categorical variables are shown as numbers and percentages. Continuous variables are presented as means with standard deviation (SD) or as medians with interquartile range (IQR) based on their distribution. Continuous variables that were not normally distributed were compared using the Mann Whitney U test. We studied early LT mortality based on GGT levels at POD 7 as a categorical variable, using tertiles (low, intermediate, and high). Similarly, we assessed the late LT mortality based on GGT levels at six months post-LT using tertiles.

Patient survival was analyzed with Kaplan-Meier analysis and the differences between the groups were assessed with the log-rank test. A $p<0.05$ was considered statistically significant.

\section{Results}

\section{Study population}

We performed a total of 968 consecutive LTs in our center between January 1990 and August 2009. After excluding pediatric LTs (age <17 yr; n=290), patients who were re-transplanted within the 90 days of their first LT $(n=39)$, second or subsequent LTs $(n=101)$, patients with a lack of follow up data $(n=11)$, and patients that died intraoperatively $(n=5)$ due to brain death, cardiac failure, or uncontrollable bleeding, 522 patients were included in our analyses. The median age was 48 years (37-56), 54\% of the patients were males, mean (SD) BMI was 24.8 ( \pm 5.3$)$, median Karnofsky score was 60 (30-70) and median MELD score was 17 (13-24) for the study population. Indications for LT were post necrotic cirrhosis (49\%), cholestatic liver disease (30\%), metabolic disease (10\%), acute liver failure $(7 \%)$, and miscellaneous (5\%). Patient characteristics and the surgical variables of the entire group of 522 patients are summarized in Table 1. 
Table 1. Characteristics of study population.

\begin{tabular}{|c|c|}
\hline Demographic characteristics & Total $n=522$ \\
\hline \multicolumn{2}{|l|}{ Recipient variables } \\
\hline Gender, male & $283(54 \%)$ \\
\hline Age, years, median (IQR) & $48(37-56)$ \\
\hline $\mathrm{BMI}$, mean $(\mathrm{SD})^{\star}$ & $25(5)$ \\
\hline Karnofsky score, median (IQR) & $60(30-70)$ \\
\hline MELD, median $(I Q R)^{\star}$ & $17(13-24)$ \\
\hline \multicolumn{2}{|l|}{ Indication for LT } \\
\hline Post necrotic cirrhosis & $254(49 \%)$ \\
\hline Cholestatic liver diseases & $155(30 \%)$ \\
\hline Acute liver failure & $38(7 \%)$ \\
\hline Metabolic disease & $51(10 \%)$ \\
\hline Miscellaneous & $24(5 \%)$ \\
\hline In hospital stay, days (IQR) & $30(21-46)$ \\
\hline ICU stay, days (IQR) & $3(2-7)$ \\
\hline \multicolumn{2}{|l|}{ Transplantation variables } \\
\hline Operation length (minutes), mean (SD) & $581(119)$ \\
\hline WIT (minutes), mean (SD) & $53(14)$ \\
\hline CIT (minutes), mean (SD) & $573(192)$ \\
\hline Combined transplant (kidney or lung) & $18(3 \%)$ \\
\hline Acute 90 day rejection & $178(34 \%)$ \\
\hline Mild, not treated & 75 (42\%) \\
\hline Moderate severe, treated & $103(58 \%)$ \\
\hline \multicolumn{2}{|l|}{ Graft type* } \\
\hline Full size & $503(97 \%)$ \\
\hline Split or reduced size & $18(3 \%)$ \\
\hline \multicolumn{2}{|l|}{ ABO compatibility* } \\
\hline Identical & $489(95 \%)$ \\
\hline Compatible & $28(5 \%)$ \\
\hline Blood loss (liters), median (IQR) & $5.0(2.1-8.5)$ \\
\hline RBC transfusion (unit=300 ml), median (IQR) & $6(2-11)$ \\
\hline \multicolumn{2}{|l|}{ Donor type* } \\
\hline Heart beating & $435(91 \%)$ \\
\hline Non-heart beating & $38(8 \%)$ \\
\hline Living donor & $3(1 \%)$ \\
\hline \multicolumn{2}{|l|}{ Venous anastomosis } \\
\hline Piggyback & $302(58 \%)$ \\
\hline Classic & $220(42 \%)$ \\
\hline \multicolumn{2}{|l|}{ Bile duct anastomosis } \\
\hline Duct to duct & $456(87 \%)$ \\
\hline Rou-X-en Y & $61(12 \%)$ \\
\hline Duct-duodenostomy & $5(1 \%)$ \\
\hline \multicolumn{2}{|l|}{ Non-anastomotic stricture, } \\
\hline 90-day, yes & $30(6 \%)$ \\
\hline
\end{tabular}

*Some variables were not available for all patients. CIT, cold ischemia time; ICU, intensive care unit; IQR, interquartile range; INR, international normalized ratio; SD, standard deviation; WIT, warm ischemia time
Mortality rates and major causes of early mortality

The overall mortality within 90 days, one year, and five years for the study cohort was $8 \%, 12 \%$, and $21 \%$, respectively. Sepsis was the major cause of mortality (37\%) within 90 days followed by multi organ failure (14\%), and brain death (9\%). Table 2 details all causes of mortality within the first 90 days.

\section{Early post-LT GGT and other liver variables and early mortality}

Early postoperative laboratory variables are shown in Figure 1. Postoperatively, GGT levels increased gradually, reaching a maximum at POD 9 and decreased thereafter. Notably, the increase in GGT levels was significantly more pronounced, i.e. deviated more from the normal range, in patients who survived more than 90 days, as compared to those who did not: 297 (178-464) vs. $172(69-271)$ $\mathrm{U} / 1, p<0.0001$, respectively. This pattern was different from that of postoperative levels of TBI, AST, and ALT. TBI was consistently and significantly lower in patients who survived more than 90 days following LT as compared to those who did. AST and ALT levels increased rapidly until POD 1 and POD 2, respectively, followed by rapid normalization thereafter. Contrary to GGT, the peak levels of AST and ALT were significantly lower in patients who survived more than 90 days following LT as compared to those who did not: AST 659 (326-1267) vs. 1201 (451-1990) U/l, $p=0.01$, and ALT 527 (280-1080) vs. 1082 (529-2631) U/l, $p=0.001$, respectively.

Thirty patients developed NAS within the 90 days post-LT. Since these patients may present with abnormal high TBI and GGT levels, we repeated the analysis with exclusion of these 30 patients with no significant affect on the GGT levels (graphical representation not shown). Also exclusion of patients who were treated for developing an acute rejection $(n=103)$ and those who underwent LT for cholestatic liver disease $(\mathrm{n}=155)$ did not significantly affect the outcomes (graphical representation not shown).

Late post-LT GGT and other liver variables and mortality Late postoperative laboratory variables are shown in Figure 2. We studied the changes in GGT levels over time in patients who survived more than five years as compared to those who did not survive. Compared to patients who died within five years post-LT,

\section{Table 2. Causes of mortality within the $\mathbf{9 0}$ days after LT.}

\begin{tabular}{|l|l|}
\hline Cause of death & Frequency $\mathbf{n = 4 3}(\%)$ \\
\hline Sepsis & $16(37 \%)$ \\
\hline Multi organ failure & $6(14 \%)$ \\
\hline $\begin{array}{l}\text { Brain death (metabolic and hepatic } \\
\text { encephalopathy) }\end{array}$ & $4(9 \%)$ \\
\hline Transplant failure & $3(7 \%)$ \\
\hline Pulmonary embolism & $3(7 \%)$ \\
\hline Bleeding & $3(7 \%)$ \\
\hline Cardiac failure & $3(7 \%)$ \\
\hline Respiratory failure & $1(2 \%)$ \\
\hline Graft vs. host disease & $1(2 \%)$ \\
\hline Unspecified & $3(7 \%)$ \\
\hline
\end{tabular}



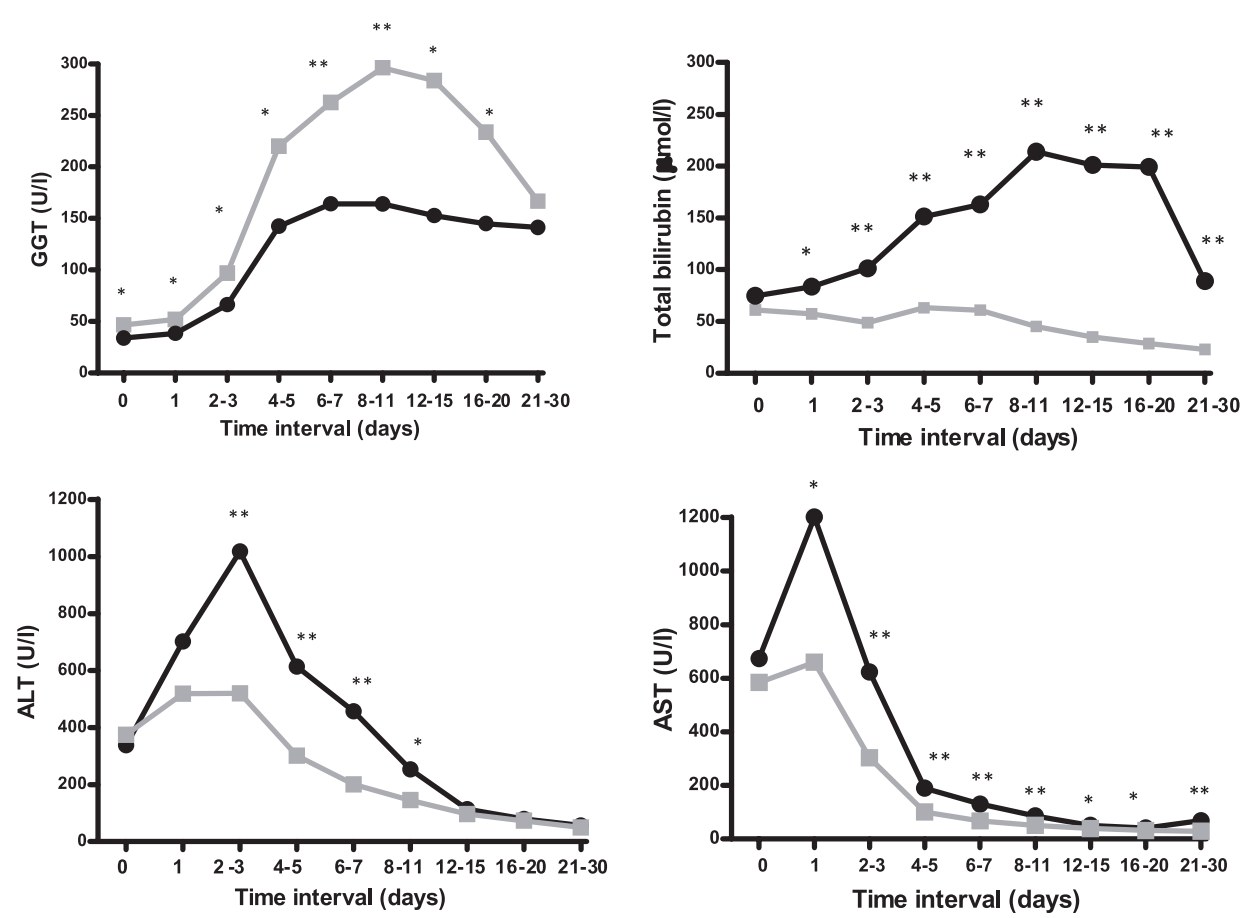

Figure 1. Evaluation of early post-LT laboratory variables (i.e. 0-30 POD) in early mortality. Curves represent patients who survived more than 90 days (gray) and those who did not (black). Median values are shown. ${ }^{*} p<0.05$; ${ }^{* \star} p \leq 0.001$. GGT, gamma glutamyl transpeptidase; ALT, aspartate aminotransferase; AST, alanine aminotransferase; TBI, total bilirubin.

those who survived more than five years had significantly lower GGT at three months post-LT; 95 (42-244) vs. 212 (92-400) U/l, $p=0.001$, six months post-LT; $70(31-189)$ vs. $281(103-438) \mathrm{U} / \mathrm{l}$, $p<0.001$, and 1 year post-LT; 57 (25-153) vs. $124(45-431) \mathrm{U} / \mathrm{l}$, $p=0.003$, respectively. Notably, late post-LT the GGT levels showed the same patterns as TBI, AST, and ALT, i.e. higher levels in non-survivors.

\section{Kaplan-Meier survival analysis}

We also studied the clinical relevance of early versus late elevated GGT levels with Kaplan-Meier survival analysis. Figure 3 plots the overall 90-day and 5-year overall survival for the study cohort based on GGT-tertiles. A high GGT level at POD 7 was significantly associated with better early survival following LT (Figure 3A). The overall 90-day survival was $98 \%$ for high GGT ( $\geq 351 \mathrm{U} / \mathrm{l})$, compared to $94 \%$ for intermediate GGT levels (188 and $350 \mathrm{U} / \mathrm{l}$ ), and $87 \%$ for the low GGT $(\leq 187 \mathrm{U} / \mathrm{l})$, at POD 7 (Figure $3 \mathrm{~A}$ ). Similarly, five-year overall survival was $86 \%, 83 \%$, and $73 \%$ for high, intermediate, and low GGT at POD 7 ( $p=0.003$; Figure 3B), respectively. Remarkably, the differences in five-year survival mainly developed during the first three months post-LT with almost no difference in survival curves thereafter (Figure 3B). In sharp contrast with early GGT, a high GGT level six months post-LT was associated with lower five-year survival (Figure 3C). The overall survival within five years was $71 \%$ for elevated GGT (> $163 \mathrm{U} / \mathrm{l})$, compared to $91 \%$ for intermediate GGT levels (44 and $163 \mathrm{U} / \mathrm{l}$ ), and $93 \%$ for the low GGT ( $<43 \mathrm{U} / 1), p<0.001$.

\section{Serum gamma glutamyl transpeptidase levels post-liver transplantation and survival data}

6 Data Files

http://dx.doi.org/10.6084/m9.figshare.900343

\section{Discussion}

In this study, we evaluated the changes in GGT over time following liver transplantation and the clinical relevance of these changes for early and late survival. We found that a transiently elevated GGT early after LT was associated with increased survival rates within the first 90 days. In contrast, late elevation of GGT was associated with decreased five-year survival following LT. Although the early GGT elevations was also associated with five-year survival, this difference mainly developed during the first 90 days post-LT.

This peculiar effect was not observed for TBI, AST, and ALT since higher levels for these parameters at POD 7 and six months were associated with increased mortality at both 90 days and five years after LT.

To our knowledge, this is the first study showing the short and long term kinetics of GGT and the clinical relevance of an early elevated serum GGT in LT recipients. Previously, we have reported improved outcome in patients with significantly increased levels of GGT in the early post-operative period following liver resection ${ }^{12}$ 

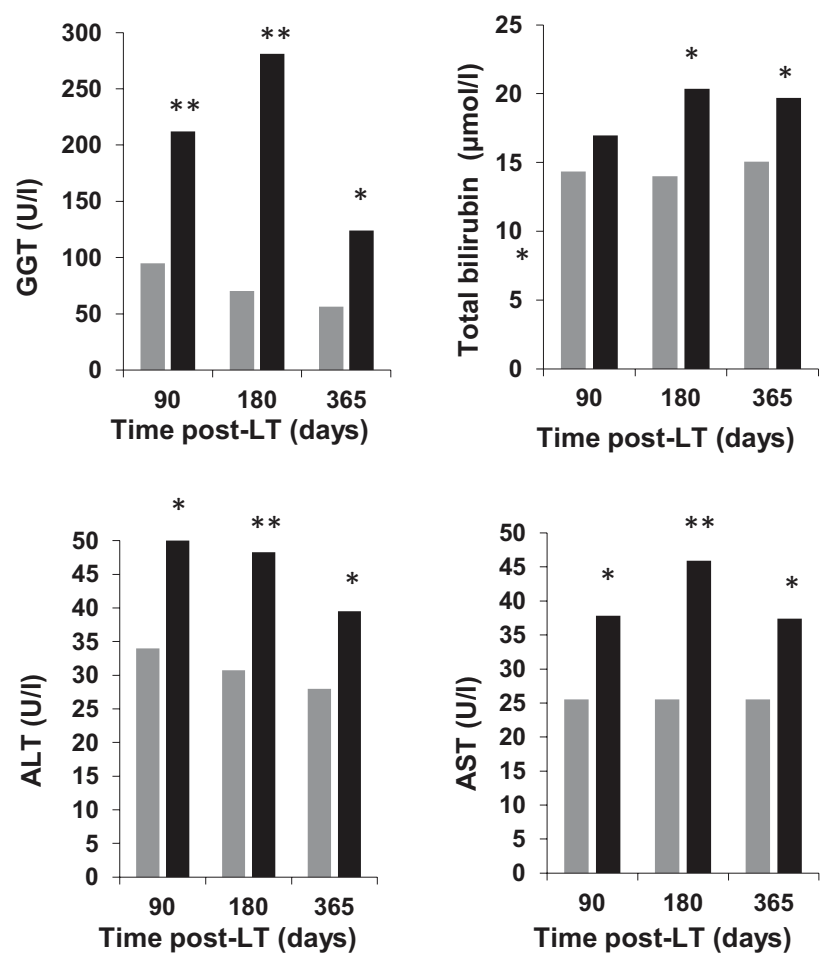

Figure 2. Evaluation of three, six, and twelve months post-LT laboratory variables in late mortality. Bars represent patients who survived more than five years (gray) and those who did not (black). Median values are shown. ${ }^{*} p<0.05 ;{ }^{* *} p \leq 0.001$. GGT, gamma glutamyl transpeptidase; ALT, aspartate aminotransferase; AST, alanine aminotransferase; TBI, total bilirubin.

and surgical repair of a ruptured abdominal aortic aneurysm ${ }^{11}$. However, those studies were not designed to address changes in GGT progression over time.

While we acknowledge that association does not necessarily indicate causation, these data support the hypothesis that high GGT in an early post-LT setting may be a marker of some protective process.

Although the precise mechanism responsible for an elevated serum GGT early after LT is yet to be determined, experimental studies have demonstrated that cellular GGT modulates crucial redox-sensitive functions, such as antioxidant and antitoxic defenses, cellular proliferation, and apoptotic balance ${ }^{13}$. Cellular GGT is a key enzyme in the gamma-glutamyl cycle resulting in production of intracellular $\mathrm{GSH}^{14-16}$, an important antioxidant agent that protects the cells against reactive oxygen species (ROS $)^{17-19}$. GSH has been shown to protect the liver against ischemia reperfusion injury in animal models ${ }^{16,20,21}$. Hepatic ischemia can cause elevation of serum GGT with peak blood levels within 20 and 30 hours after restoration of hepatic arterial blood flow ${ }^{18,24}$. Reperfusion is associated with a surge of ROS, which may overwhelm host natural antioxidant defenses $^{21}$. The oxidative stress from the ROS formed after reperfusion may lead to increased cellular death by damaging membrane lipids through peroxidation, disrupting normal enzymatic activities, and diminishing mitochondrial oxidative metabolism ${ }^{22}$. Cardin and colleagues ${ }^{23}$ studied oxidative stress in patients with chronic hepatitis
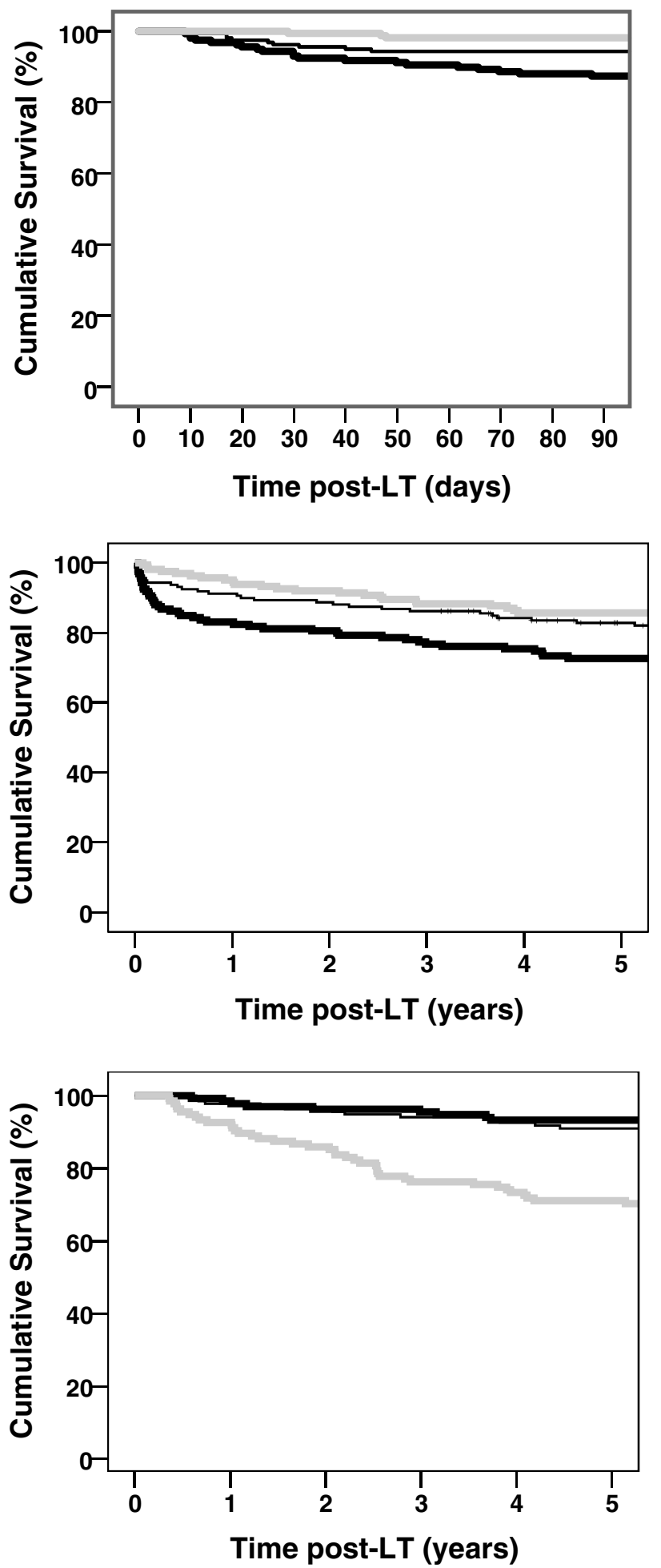

Figure 3. Kaplan-Meier analysis showing the opposite relationships of early and late GGT levels with early and late mortality. Panels A and B represent survival analysis post-LT in relation to GGT tertiles at POD 7 , within 90 days and five years respectively $(p=0.003)$. Panel $\mathrm{C}$ demonstrates five-year survival in relation to GGT tertiles at six months post-LT $(p<0.001)$. Curves represent low (thick black), intermediate (thin black), and high GGT (gray). 
$\mathrm{C}$ virus infection. Surprisingly, the authors observed an association between GGT and 8-hydroxydeoxyguanosine (8-OHdG), a marker of oxidative DNA damage. Patients who had a high level of 8-OHdG had significantly higher GGT levels but normal ALT levels ${ }^{23}$.

Thus, a transient increase in GGT level post-LT may reflect the host compensatory mechanism against oxidative stress and toxic metabolites generated by hypoxia, reperfusion, and surgical stress ${ }^{21}$. Therefore, an increased GGT early after LT may reflect the ability of the host to initiate an appropriate systemic response.

Another explanation for the elevated serum GGT in the early post-LT period that has been suggested relates to liver regeneration. Eisenbach and colleagues ${ }^{25}$, showed that an early increase in serum GGT after LT was associated with a better outcome and the authors reasoned that this rise could be due to liver regeneration. Although the liver might regenerate to some extent after LT, there is no conclusive evidence to support this hypothesis. As we mentioned earlier, we observed a transient increase in serum GGT levels in patients who survived a surgical repair for a ruptured abdominal aortic aneurysm ${ }^{11}$. In the latter group, it is less likely that significant liver regeneration occurs.

Contrary to early elevated GGT, but in line with published literature $^{2-10}$, we observed that a late (i.e. six months post-LT) elevated GGT was significantly associated with decreased survival within the 5-years following LT. Although the finding that normal GGT levels in the late post-operative period is predictive of good outcomes is obvious and intuitive, the contrasting influences of GGT levels between early and late post-LT periods on survival may be compatible with the physiologic function of intracellular GGT. Notably, at three months, six months, and one year post-LT, the relative increase in serum GGT was two to four times higher in patients who did not survive for more than five years compared to those who did survive. This proportion was much higher than that of AST, ALT and TBI, which might imply that an elevated serum GGT is not only a marker of harm to the liver but it could be seen as a systemic response to harmful environmental factors. Indeed, in two studies, Lee and colleagues ${ }^{26,27}$ postulated that serum GGT in the general population might be a marker of increased exposure to environmental stress, internal xenobiotics, or other unknown factors that cause oxidative stress in the long run.

To avoid possible bias we performed our analysis after excluding obstructive mechanisms such as NAS, cholestatic disorders, and acute graft rejection early postoperatively. Exclusion of these cases did not change our results significantly, suggesting that the elevation in serum GGT early post-LT is independent of obstructive disorders.

A practical clinical consequence of our findings may be that care providers in hospitals should realize that an abnormally high GGT early post-LT is not a cause for alarm or specific diagnostic procedures. In fact, a GGT activity four to five times above the normal range during the second post-operative week might even be considered beneficial.

We acknowledge some considerable limitations in this study. First, due to the retrospective design of the study we can only identify association rather than causation. This could only be established by specific (intervention) studies that measure the interaction between serum GGT and ROS markers post-LT. However, there is a strong correlation between GGT and oxidative DNA damage in cirrhotic patients $^{23}$. Next, we cannot entirely exclude that liver regeneration plays a role in the early post-LT rise of GGT levels since GSH and to some extent GGT are mainly produced by the liver ${ }^{1}$. Hence a high serum GGT in patients who survived more than 90 days can also be a reflection of a well-functioning graft in LT patients. It will be important to understand the relationship of serum GGT and cellular GGT in the period immediately after surgery. Besides, cumulative evidence suggests that there is a relationship between the induction and release of ROS and ischemia reperfusion injury after other types of abdominal surgery ${ }^{18,21,24}$.

In conclusion, an elevated GGT level early after LT was associated with a better short-term outcome. However, chronically elevated GGT was associated with poor long-term outcome in the outpatient setting after LT. This peculiar switch in the prognostic meaning of GGT may result from the superposition of several mechanisms. Apparently, higher expression of GGT protects in the acute phase but reflects chronic damage over the long term.

\section{Data availability}

figshare: Serum gamma glutamyl transpeptidase levels post-liver transplantation and survival data, http://dx.doi.org/10.6084/ m9.figshare. $900343^{28}$

\section{Author contributions}

The study was conceived by EMA, TJL, RJP, and MWN. Data acquisition and analysis were performed by EMA and MWN. The paper was written by EMA, TJL, RJP and MWN.

\section{Competing interests}

No competing interests were disclosed.

\section{Grant information}

This study was sponsored in part by a Mozaiek grant of the Dutch Organisation of Scientific Research (017.007.115) to Edris Alkozai.

The funders had no role in study design, data collection and analysis, decision to publish, or preparation of the manuscript.

Acknowledgments

We thank J. T. Bottema for providing us with additional data. 
1. Whitfield JB: Gamma glutamyl transferase. Crit Rev Clin Lab Sci. 2001; 38(4): 263-355. PubMed Abstract | Publisher Full Text

2. Fraser A, Harris R, Sattar N, et al.: Alanine aminotransferase, gammaglutamyltransferase, and incident diabetes: the British Women's Heart and Health Study and meta-analysis. Diabetes Care. 2009; 32(4): 741-50.

PubMed Abstract | Publisher Full Text | Free Full Text

3. Kazemi-Shirazi L, Endler G, Winkler S, et al:: Gamma glutamyltransferase and long-term survival: is it just the liver? Clin Chem. 2007; 53(5): 940-6. PubMed Abstract | Publisher Full Text

4. Kristenson H, Ohrn J, Hood B: Convictions for drunkenness or drunken driving sick absenteeism, and morbidity in middle-aged males with different levels of serum gamma-glutamyltransferase. Prev Med. 1982; 11(4): 403-16. PubMed Abstract | Publisher Full Text

5. Strasak AM, Kelleher CC, Klenk J, et al.: Longitudinal change in serum gammaglutamyltransferase and cardiovascular disease mortality: a prospective population-based study in $\mathbf{7 6 , 1 1 3}$ Austrian adults. Arterioscler Thromb Vasc Biol. 2008; 28(10): 1857-65.

PubMed Abstract | Publisher Full Text | Free Full Text

6. Peterson B, Trell E, Kristensson $\mathrm{H}$, et al:: Comparison of gamma-glutamyltransferase and other health screening tests in average middle-aged males, heavy drinkers and alcohol non-users. Scand J Clin Lab Invest. 1983; 43(2): 141-9. PubMed Abstract | Publisher Full Text

7. Lee DS, Evans JC, Robins SJ, et al:: Gamma glutamyl transferase and metabolic syndrome, cardiovascular disease, and mortality risk: the Framingham Heart Study. Arterioscler Thromb Vasc Biol. 2007; 27(1): 127-33. PubMed Abstract | Publisher Full Text

8. Ruttmann E, Brant LJ, Concin H, et al:: Gamma-glutamyltransferase as a risk factor for cardiovascular disease mortality: an epidemiological investigation in a cohort of 163,944 Austrian adults. Circulation. 2005; 112(14): 2130-7. PubMed Abstract | Publisher Full Text

9. Breitling LP, Claessen H, Drath C, et al.: Gamma-glutamyltransferase, general and cause-specific mortality in 19,000 construction workers followed over 20 years. J Hepatol. 2011; 55(3): 594-601. PubMed Abstract | Publisher Full Text

10. Kengne AP, Czernichow S, Stamatakis E, et al: Gamma-glutamyltransferase and risk of cardiovascular disease mortality in people with and without diabetes: pooling of three British Health Surveys. J Hepatol. 2012; 57(5): 1083-9. PubMed Abstract | Publisher Full Text

11. Haveman JW, Zeebregts CJ, Verhoeven EL, et al: Changes in laboratory values and their relationship with time after rupture of an abdominal aortic aneurysm. Surg Today. 2008; 38(12): 1091-101. PubMed Abstract | Publisher Full Text

12. Alkozai EM, Lisman T, Porte RJ: Bleeding in liver surgery: prevention and treatment. Clin Liver Dis. 2009; 13(1): 145-54. PubMed Abstract | Publisher Full Text

13. Kobayashi $\mathrm{H}$, Nonami $\mathrm{T}$, Kurokawa $\mathrm{T}$, et al:: Changes in the glutathione redox system during ischemia and reperfusion in rat liver. Scand J Gastroenterol. 1992; 27(8): 711-6. PubMed Abstract | Publisher Full Text

14. Moriya S, Nagata S, Yokoyama $\mathrm{H}$, et al.: Expression of gamma-glutamyl transpeptidase mRNA after depletion of glutathione in rat liver. Alcohol Alcohol Suppl. 1994; 29(1): 107-11.

PubMed Abstract
15. Rajpert-De Meyts E, Shi M, Chang M, et al.: Transfection with gamma-glutamyl transpeptidase enhances recovery from glutathione depletion using extracellular glutathione. Toxicol Appl Pharmacol. 1992; 114(1): 56-62. PubMed Abstract | Publisher Full Text

16. Stein $\mathrm{HJ}$, Oosthuizen MM, Hinder RA, et al:: Oxygen free radicals and glutathione in hepatic ischemia/reperfusion injury. J Surg Res. 1991; 50(4): 398-402. PubMed Abstract | Publisher Full Text

17. Stenius $U$, Rubin $\mathrm{K}$, Gullberg D, et al.: gamma-Glutamyltranspeptidase-positive rat hepatocytes are protected from GSH depletion, oxidative stress and reversible alterations of collagen receptors. Carcinogenesis. 1990; 11(1): 69-73. PubMed Abstract | Publisher Full Text

18. Stastny $\mathrm{F}$, Lisy $\mathrm{V}$, Tomasova $\mathrm{H}$, et al:: Effects of short-term and prolonged aerogenic hypoxia on gamma-glutamyl transpeptidase activity in the brain, liver, and biological fluids of young rats. Neurochem Res. 1985; 10(6): 819-28. PubMed Abstract | Publisher Full Text

19. Gupta S, Rajvanshi P, Malhi H, et al:: Cell transplantation causes loss of gap junctions and activates GGT expression permanently in host liver. Am J Physiol Gastrointest Liver Physiol. 2000; 279(4): G815-26. PubMed Abstract

20. Schauer RJ, Gerbes AL, Vonier D, et al:: Glutathione protects the rat liver against reperfusion injury after prolonged warm ischemia. Ann Surg. 2004; 239(2): 220-31.

PubMed Abstract | Publisher Full Text | Free Full Text

21. Zhang W, Wang M, Xie HY, et al.: Role of reactive oxygen species in mediating hepatic ischemia-reperfusion injury and its therapeutic applications in liver transplantation. Transplant Proc. 2007; 39(5): 1332-7. PubMed Abstract | Publisher Full Text

22. Nonn L, Berggren M, Powis G: Increased expression of mitochondrial peroxiredoxin-3 (thioredoxin peroxidase-2) protects cancer cells against hypoxia and drug-induced hydrogen peroxide-dependent apoptosis. Mol Cancer Res. 2003; 1(9): 682-9.

PubMed Abstract

23. Cardin R, Saccoccio G, Masutti F, et al.: DNA oxidative damage in leukocytes correlates with the severity of HCV-related liver disease: validation in an open population study. J Hepatol. 2001; 34(4): 587-92. PubMed Abstract | Publisher Full Text

24. Liu W, Schob O, Pugmire JE, et al:: Glycohydrolases as markers of hepatic ischemia-reperfusion injury and recovery. Hepatology. 1996; 24(1): 157-62. PubMed Abstract | Publisher Full Text

25. Eisenbach $\mathrm{C}$, Encke $\mathrm{J}$, Merle $\mathrm{U}$, et al: An early increase in gamma glutamyltranspeptidase and low aspartate aminotransferase peak values are associated with superior outcomes after orthotopic liver transplantation. Transplant Proc. 2009; 41(5): 1727-30 PubMed Abstract | Publisher Full Text

26. Lee $\mathrm{DH}$, Blomhoff $\mathrm{R}$, Jacobs $\mathrm{DR}$ Jr: Is serum gamma glutamyltransferase marker of oxidative stress? Free Radic Res. 2004; 38(6): 535-9. PubMed Abstract | Publisher Full Text

27. Lee $\mathrm{DH}$, Gross MD, Steffes MW, et al:: Is serum gamma-glutamyltransferase a biomarker of xenobiotics, which are conjugated by glutathione? Arterioscler Thromb Vasc Biol. 2008; 28(4): e26-8; author reply e29. PubMed Abstract | Publisher Full Text

28. Alkozai EM, Lisman T, Porte RJ, et al:: Serum gamma glutamyl transpeptidase levels post-liver transplantation and survival data. Figshare. 2014 Data Source 


\section{Open Peer Review}

\section{Current Peer Review Status:}

\section{Version 1}

Reviewer Report 10 July 2014

https://doi.org/10.5256/f1000research.3557.r5247

(c) 2014 Jansen P. This is an open access peer review report distributed under the terms of the Creative Commons Attribution License, which permits unrestricted use, distribution, and reproduction in any medium, provided the original work is properly cited.

\section{Peter Jansen}

Division of Gastroenterology and Liver Diseases, University of Amsterdam, Amsterdam, The Netherlands

This is an interesting paper providing novel insights into the value of traditional serum markers. It is quite true that the understanding of elevated GGT values is very limited, despite the fact that this value is one of the most requested 'liver function tests'. Most clinicians who request this test probably have no clear understanding what is being tested. It is very interesting that elevated GGT shortly after liver transplantation is associated with a better outcome.

The title, abstract, data section, statistics and figures of the paper are OK, the discussion section could be a little more to the point.

In my opinion there might be two reasons for an elevated GGT early after transplantation: 1) Elevated GGT is associated with oxidative stress, and some oxidative stress may prompt the hepatocyte to activate innate protective mechanisms; 2) Elevated GGT after transplantation may be an indicator of good early secretory function of the liver. GGT in part comes from the surface of the bile ducts and is released from the anchor which attaches this enzyme to the cell surface, by bile acids in bile. These same authors have shown that immediately after transplantation the bile acid/phospholipid ratio in bile is elevated and (as in MDR3 deficient/LPAC patients) this leads to elevated GGT. Thus elevated GGT immediately after transplantation indicates an active bile flow. This protects hepatocytes from cytotoxic bile acids. Later after transplantation when the BA/PL ratio has normalized, bile has lost some of its detergent action, with lower basal serum GGT levels as a result. When GGT is elevated at this stage it has become the traditional indicator of liver damage associated with a bad outcome, as the authors indicate.

If the authors agree with this reasoning they could include some of these thoughts in the discussion section, in order to provide a little bit more insight into why elevation under some 
conditions may be beneficial as this, in my opinion, is the main and novel message of this paper.

Competing Interests: No competing interests were disclosed.

I confirm that I have read this submission and believe that I have an appropriate level of expertise to confirm that it is of an acceptable scientific standard.

Author Response 10 Aug 2014

Edris M Alkozai, University Medical Center Gronignen, The Netherlands

We thank Prof. Jansen for reviewing our paper and for his exclusive discussion about potential mechanisms responsible for elevation of GGT early after transplantation.

Prof. Jansen postulates two plausible reasons for increased GGT early after transplantation: the association of GGT with oxidative stress as we pointed out in our paper, and an indication of good early secretory function of the liver after transplantation that protects the hepatocytes from cytotoxic bile acids. Prof. Jansen also implies that the imbalance between the bile acids and phospholipids describes the underling mechanism of the damage to the hepatocytes early after transplantation, which disappears late after transplantation. We agree with Prof. Jansen and have included his valuable points into our discussion.

Competing Interests: We have no competing interests.

Reviewer Report 22 April 2014

https://doi.org/10.5256/f1000research.3557.r4362

(C) 2014 Olausson $\mathbf{M}$. This is an open access peer review report distributed under the terms of the Creative Commons Attribution License, which permits unrestricted use, distribution, and reproduction in any medium, provided the original work is properly cited.

\section{Michael Olausson}

Department of Surgery, University of Gothenburg, Gothenburg, Sweden

This is a very useful paper on Gamma Glutamyl Transpeptidase (GGT or just GT) - a test used in many liver transplant units and in hepatologist outpatient clinics. Its main use is the proposed correlation to liver damage - may it be cholestasis (often in combination with ALP elevation), rejection or infection. It is also used in alcoholic abuse monitoring. The early kinetics after liver transplantation are less known, and this paper gives valuable information regarding this.

The authors found that livers with longterm function had an early raise in GT levels, not indicating signs of liver damage, while late raised levels showed the more expected liver damage as reason. Possible causes for early elevated levels are discussed, and a very relevant review article written by Whitfield (2001) is recommended. 
Title:

The title reflects the take home message.

\begin{abstract}
:
I think the abstract should stress the connection to oxidative stress mentioned in the review article more, since this seems to be a very plausible mechanism.
\end{abstract}

\title{
Methods:
}

The study is well conducted and patient selection well explained. The validity check of the findings by excluding NAS and cholestatic patients strengthen the results.

\section{Conclusions:}

The conclusions could merit from referring to the correlation to oxidative stress more. It is not proven that higher early GT actually protects the liver - it could be a surrogate marker for a liver in less oxidative stress.

Competing Interests: No competing interests were disclosed.

\section{I confirm that I have read this submission and believe that I have an appropriate level of expertise to confirm that it is of an acceptable scientific standard.}

\section{Author Response 10 Aug 2014}

Edris M Alkozai, University Medical Center Gronignen, The Netherlands

We would like to thank Prof. Olausson for his constructive and encouraging comments. We agree with Prof. Olausson that the oxidative stress might be a very plausible mechanism. As Dr. Olausson suggested, we have changed the abstract so that it now better reflects the role of GGT in oxidative stress.

With regard to the conclusion in the discussion, Prof. Olausson points to an important issue. These data do not prove that the higher early GGT protects the liver. In our discussion we did mention that GGT is associated with better outcome and that this association does not necessarily indicate causation. Thus, our data can only support the hypothesis that high GGT in an early post-transplantation setting may be a marker of some protective process. Accordingly, we have changed that last sentence in our conclusion.

Competing Interests: No competing interests were disclosed. 
The benefits of publishing with F1000Research:

- Your article is published within days, with no editorial bias

- You can publish traditional articles, null/negative results, case reports, data notes and more

- The peer review process is transparent and collaborative

- Your article is indexed in PubMed after passing peer review

- Dedicated customer support at every stage

For pre-submission enquiries, contact research@f1000.com 